\title{
Evaluation of Components of Fusarium Head Blight Resistance in Soft Red Winter Wheat Germ Plasm Using a Detached Leaf Assay
}

\author{
R. A. Browne, Department of Environmental Resource Management, University College Dublin, Belfield, Dublin 4, \\ Ireland; J. P. Murphy, Department of Crop Science, North Carolina State University, Raleigh 27695; B. M. Cooke and \\ D. Devaney, Department of Environmental Resource Management, University College Dublin, Belfield, Dublin 4, Ire- \\ land; E. J. Walsh, Department of Crop Science, Horticulture and Forestry, University College Dublin, Belfield, Dublin \\ 4, Ireland; C. A. Griffey, Department of Crop and Soil Environmental Sciences, Virginia Tech, Blacksburg, VA 24061; \\ J. A. Hancock, Syngenta Seeds, Inc., Bay, AR 72411; S. A. Harrison, Department of Agronomy, Louisiana State Uni- \\ versity, Baton Rouge 70803; P. Hart, Dept. of Plant Pathology, Michigan State University, East Lansing 48824; \\ F. L. Kolb, Department of Crop Sciences, University of Illinois, Urbana 61801; A. L. McKendry, Department of \\ Agronomy, University of Missouri, Colombia 65211; E. A. Milus, Department of Plant Pathology, University of Arkan- \\ sas, Fayetteville 72701; C. Sneller, Department of Crop Science and Horticulture, Ohio State University, Wooster \\ 44691; and D. A. Van Sanford, Department of Agronomy, University of Kentucky, Lexington 40546
}

\begin{abstract}
Browne, R. A., Murphy, J. P., Cooke, B. M., Devaney, D., Walsh, E. J., Griffey, C. A., Hancock, J. A., Harrison, S. A., Hart, P., Kolb, F. L., McKendry, A. L., Milus, E. A., Sneller, C., and Van Sanford, D. A. 2005. Evaluation of components of Fusarium head blight resistance in soft red winter wheat germ plasm using a detached leaf assay. Plant Dis. 89:404-411.

A large environmental influence on phenotypic estimates of disease resistance and the complex polygenic nature of Fusarium head blight (FHB) resistance in wheat (Triticum aestivum) are impediments to developing resistant cultivars. The objective of this research was to investigate the utility of a detached leaf assay, inoculated using inoculum from isolates of Microdochium nivale var. majus, to identify components of FHB resistance among 30 entries of U.S. soft red winter wheat in the 2002 Uniform Southern FHB Nursery (USFHBN). Whole plant FHB resistance of the USFHBN entries was evaluated in replicated, mist-irrigated field trials at 10 locations in eight states during the 2001-2002 season. Incubation period (days from inoculation to the first appearance of a dull gray-green water-soaked lesion) was the only detached leaf variable significantly correlated across all FHB resistance parameters accounting for $45 \%$ of the variation in FHB incidence, $27 \%$ of FHB severity, 30\% of Fusarium damaged kernels, and $26 \%$ of the variation in grain deoxynivalenol (DON) concentration. The results for incubation period contrasted with previous studies of moderately resistant European cultivars, in that longer incubation period was correlated with greater FHB susceptibility, but agreed with previous findings for the Chinese cultivar Sumai 3 and CIMMYT germ plasm containing diverse sources of FHB resistance. The results support the view that the detached leaf assay method has potential for use to distinguish between specific sources of FHB resistance when combined with data on FHB reaction and pedigree information. For example, entry 28 , a di-haploid line from the cross between the moderately resistant U.S. cultivar Roane and the resistant Chinese line W14, exhibited detached leaf parameters that suggested a combination of both sources of FHB resistance. The USFHBN represents the combination of adapted and exotic germ plasm, but four moderately resistant U.S. commercial cultivars (Roane, McCormick, NC-Neuse, and Pat) had long incubation and latent periods and short lesion lengths in the detached leaf assay as observed in moderately FHB resistant European cultivars. The dichotomy in the relationship between incubation period and FHB resistance indicates that this may need to be considered to effectively combine exotic and existing/adapted sources of FHB resistance.
\end{abstract}

Fusarium head blight (FHB) is a major problem in cereal production worldwide, with wheat (Triticum aestivum L.) and barley (Hordeum vulgare L. subsp. vul-

Corresponding author: R. A. Browne

E-mail: roy.browne@ucd.ie

This research was supported in part by the U.S. Wheat and Barley Scab Initiative.

Accepted for publication 23 November 2004.

DOI: 10.1094/PD-89-0404

(C) 2005 The American Phytopathological Society rum predominates as the causal agent of FHB in the United States $(22,25,27)$. $M$. nivale has occasionally caused FHB in northwestern Washington, but it is primarily noted as the causal agent of pink snow mold (26). There is no strong evidence for species-specific resistance in wheat to any of the fungal species implicated in the FHB complex (18).

The incorporation of genetically diverse sources of resistance has been an objective of breeders in the development of cultivars with effective and stable FHB resistance. Progress has been hampered by the relatively large environmental effect on phenotypic estimates of resistance (4), the complex polygenic nature of FHB resistance, and the widespread use of exotic (typically Asian) germ plasm by western breeding programs (19). Exotic donor sources of germ plasm such as the Chinese Sumai 3 frequently have poor winter survival and straw strength, and greater susceptibility to other economically important diseases and insects $(5,15,16)$. Soft red winter wheat breeders in the United States have identified moderate levels of resistance to FHB in cultivars such as 'Ernie' and 'Freedom' $(10,14,19)$. The sources of this resistance are not readily evident from examination of pedigrees, but it is unlikely to be traced to known Asian sources. One potential source of resistance is the Brazilian cultivar Frontana that is ubiquitous in the pedigrees of U.S. soft red winter wheat cultivars (7). This cultivar was utilized as a source of resistance to leaf rust (caused by Puccinia triticina $[=P$. recondita Roberge ex Desmaz. f. sp. tritici]) by U.S. wheat breeders and is known to exhibit FHB resistance (24).

There is no complete resistance to FHB in wheat, although many sources of partial resistance have been identified. Partial disease resistance is characterized by a reduced rate of epidemic development in a host population attributed to various components of partial disease resistance including lower infection frequency and 
longer latent period (period from inoculation to sporulation) (11). These partial disease resistance components follow directly from the differential-difference equation proposed by Vanderplank (23) as a model for epidemic development.

Diamond and Cooke (8) and Browne and Cooke (2) utilized a detached leaf assay to relate incubation period (time from inoculation to the first appearance of a dull gray-green water-soaked lesion), latent period (time from inoculation to sporulation), and lesion length to moderate levels of FHB resistance in European cultivars. $M$. nivale was utilized in the assay because it provided far more distinct and readily observable symptoms on detached leaves than other members of the FHB complex (2). Longer incubation and latent periods were significantly related to greater whole-plant FHB resistance (type I) in Irish and UK commercial cultivars of wheat with no known Asian resistance sources in their pedigrees $(2,8)$. These correlations were greatest for latent period and whole-plant FHB resistance (2). In contrast, the authors did not find a similar relationship between the detached leaf assay and whole-plant FHB resistance in CIMMYT genotypes containing more diverse sources of resistant germ plasm in their pedigrees (2). The detached leaf assay did not appear to detect the wholeplant resistance of Sumai 3 because this cultivar displayed shorter incubation and latent periods and longer lesion lengths relative to the European commercial cultivars. Also, the detached leaf technique did not detect the greater FHB resistance of Frontana because this genotype had a comparable incubation period, latent period, and lesion length to the most resistant Irish and UK cultivars that possess only moderate FHB resistance (2). Browne and Cooke (2) hypothesized that while the detached leaf assay identifies components of partial disease resistance against FHB of importance in moderately resistant European wheat, other components of resistance expressed in the wheat head were not detected, particularly in exotic germ plasm.

While the reason for the divergent relationship for incubation period and FHB susceptibility between adapted and exotic germ plasm was unclear, the need for further investigation of the relationship between whole-plant FHB resistance and incubation and latent period measured in the detached leaf assay was evident (2). Recent research has shown that resistance to FHB is found in a diversity of germ plasm sources that frequently differed with respect to the chromosomal regions governing resistance $(12,13,17,21,24)$. The detached leaf assay was successful in identification of an important component of the resistances to FHB in European wheat germ plasm and may have utility as a mechanism for discrimination among different resistances in breeding programs. The objective of this research was to investigate the utility of the detached leaf assay in identification of whole-plant FHB field resistance in advanced U.S. soft red winter wheat lines and cultivars.
MATERIALS AND METHODS

Experiment 1. USFHBN entries. Thirty U.S. soft red winter wheat lines entered in the 2002 Uniform Southern Fusarium Head Blight Nursery (USFHBN) were evaluated in vitro in Dublin, Ireland, using a detached leaf assay inoculated with $M$. nivale (2) (Table 1). The entries were also evaluated for FHB resistance in 10 replicated field nurseries in the United States that were inoculated with $F$. graminearum. The 30 entries included control cultivars Ernie (entry 1, moderately FHB resistant) and Coker 9835 (entry 2, FHB susceptible). The remaining 28 entries were advanced generation breeding lines from public universities in Arkansas (AR), Georgia (GA), Maryland (MDV), North Carolina (NC), and Virginia (VA), and the private sector companies Syngenta (B) and Agripro (D). All entries were adapted to the southeastern United States and represented diverse pedigrees. Some pedigrees included known Asian sources of resistance to FHB (e.g., entries 6, 25 to 30) and known U.S. sources of moderate resistance (e.g., entry 20). Approximately one-half of the entries had undergone previous screening for FHB reaction prior to submission to the uniform nursery.

Detached leaf assay (autumn 2002 to spring 2003). All wheat entries evaluated using the detached leaf assay were grown in a controlled environment chamber for 14 days at University College Dublin. Segments $4 \mathrm{~cm}$ in length from the midsection of the first expanding seedling leaf were harvested and placed on the surface

Table 1. Entries and their pedigrees in the 2002 Uniform Southern Fusarium Head Blight Nursery

\begin{tabular}{|c|c|c|}
\hline Entry no. & Entry & Pedigree \\
\hline 1 & ERNIE & PIKE /3/ STODDARD / BLUEBOY // STODDARD / D1707 \\
\hline 2 & COKER 9835 & CK68-19 // CK61-19*3 / IN4946A4-18-2-10-2 /4/ Bb /3/ CK65-20*5 / W17-TRANS // TIFT /5/ P 2550 \\
\hline 3 & AR93095-4-1 & BAYLES / FUNDULEA 29 \\
\hline 4 & AR93035-4-2 & PIONEER 2548 / 4549-W1-2 \\
\hline 5 & AR93035-7-1 & PIONEER 2548 / 4549-W1-2 \\
\hline 6 & AR922-5-1 & AR358-4-1 / YMI 6 \\
\hline 7 & B961378 & PS840061 / SALUDA // COKER 9877 \\
\hline 8 & B980416 & COKER 9543 / ABI85-81 \\
\hline 9 & B980582 & L881061 / L880436 \\
\hline 10 & D98*9762 & SW85*5377 / PION 2555 \\
\hline 11 & D98*9764 & SW85*5377 / PION 2555 \\
\hline 12 & D98*9770 & 89D-4776 / PION 2555 \\
\hline 13 & D98-9213 & COKER 9134 / PION 2555 \\
\hline 14 & D97-6075 & PION 2545 / 89M-4032A \\
\hline 15 & GA931241E16 & COKER $9134 / 881502$ \\
\hline 16 & GA93052E42 & $841266 / 881404 / / 831378$ \\
\hline 17 & GA931463E27 & $87583 / 87467$ \\
\hline 18 & GA931470E62 & $83484 / 87467$ \\
\hline 19 & GA921233E17 & GORE $* 2 / 83267$ \\
\hline 20 & MDV11-52 & COKER 9803 / FREEDOM \\
\hline 21 & NC98-22251 & STELLA / KS85WGRC01 // COKER 9733 /3/ COKER 86-29 (HF RES) \\
\hline 22 & NC98-26189 & P81401A1-42-1 / SALUDA /3/ P 2555 / COKER 9907 // MV14 / WAKEFIELD \\
\hline 23 & NC98-26192 & P81401A1-42-1 / SALUDA /3/ P 2555 / COKER 9907 // MV14 / WAKEFIELD \\
\hline 24 & NC98-27513 & P81401A1-42-1 / SALUDA /3/ P 2555 / COKER 9907 // MV14 / WAKEFIELD \\
\hline 25 & VA01W447 & WUHAN1 // 90-52-82 / CK9835 /3/ C9803, F6 \\
\hline 26 & VA01W461 & $\begin{array}{l}\text { PC-11(SHANGHAI4 / CHILL"S":SCAB-RES) /3/ 92-51-39(IN71761A4-31-5-48 // 71-54-147 // MCN1813) // } \\
\text { FFR555W / RCT /4/ CK9803,F6 }\end{array}$ \\
\hline 27 & VA01W462 & PC-7(CHILL"S" / YM16:SCAB-RES) /3/ 92-51-39 // CK9803 / RCT /4/ 93-52-55, F6 \\
\hline 28 & VA01W476 & ROANE/W14, H2 \\
\hline 29 & VA00W566 & PC-7(CHILL"S" / YM16:SCAB-RES) / PION2548 // PION2684, F6 \\
\hline 30 & VA00W562 & PC-7(CHILL"S" / YM16:SCAB-RES) / PION2548 // PION2684, F6 \\
\hline
\end{tabular}


of $0.5 \%$ water agar (four leaves per petri dish) containing kinetin at $10 \mathrm{mg} \mathrm{liter}^{-1}$ as a senescence retarder (2). Single-spore isolates of $M$. nivale var. majus isolated from wheat seed from the 2001 harvest in Ireland were screened to ensure they had intermediate pathogenicity to detached leaves (2) and stored at $-70^{\circ} \mathrm{C}$. Myceliumfree conidial inoculum of $M$. nivale was produced on potato dextrose agar covered in cellophane (CPDA), as previously reported (1), and incubated on cool plates (6) for 7 days under a diurnal cycle of nearultraviolet (NUV) and white light.

Leaf segments were inoculated at the center of the adaxial surface with a $10-\mu \mathrm{l}$ droplet of $M$. nivale spore suspension adjusted to $1 \times 10^{6}$ conidia per $\mathrm{ml}$. The detached leaves were then incubated at $10^{\circ} \mathrm{C}$ under a 24-h diurnal cycle of NUV and white light in a standard laboratory incubator. Assessments of symptom appearance and sporulation were carried out daily under a compound microscope $(\times 40$ magnification). The components of partial disease resistance measured were incubation period (days from inoculation to first symptom development, a dull gray-green water-soaked lesion), latent period (days from inoculation to sporulation), and lesion length (measured on day 7 as the necrotic area visible by placing the petri dishes over a light box).

In addition to the 30 USFHBN entries, four control cultivars, previously evaluated for PDR components in the detached leaf assay (2), were included. These were Alexandria, an FHB susceptible cultivar from Ireland; Solstice, a moderately resistant cultivar from the United Kingdom; Sumai 3, a resistant cultivar from China; and Frontana, a resistant cultivar from South America. The detached leaf assay was repeated in three separate replicated experiments. Each experiment utilized a randomized complete block design with five replicates. An experimental unit consisted of eight detached leaves (four leaves $\times$ two petri dishes) inoculated with one isolate of $M$. nivale var. majus. Five different isolates (replications) of M. nivale var. majus were utilized in each experiment. The same isolates were used over all three experiments. The overall entry means across all three replicated detached leaf assay experiments were based on observations on 120 detached leaves.

$F$. graminearum-inoculated field nursery evaluations. The 30 entries in the USFHBN were evaluated in replicated field nurseries at 10 locations during the 2001-2002 season: Bay, Kibler, and Fayetteville, AR; Baton Rouge, LA; Kinston, NC; Blacksburg, VA; Wooster, OH; Lexington, KY; Urbana, IL; and Colombia, MO. Details of methodologies utilized at each location were published at www.scabusa.org/pdfs_dbupload/02_SUS RWWN_Rep.pdf (verified September, 2004). In summary, experiments were planted between September and December 2001 in randomized complete block designs with two to four replications. Plot size varied from a single row $0.9 \mathrm{~m}$ long to four rows, each $1.5 \mathrm{~m}$ long spaced $18 \mathrm{~cm}$ apart. All nurseries were inoculated by distributing infected corn (Zea mays) or wheat kernels prior to heading, or by spraying plots with a conidial suspension at anthesis. Field isolates of $F$. graminearum were utilized in inoculum preparation, and different isolates were utilized at each location. Overhead mist irrigation was applied postinoculation at all locations.

Data were recorded for the following variables in spring 2002: Incidence (8 locations), estimated as the percentage of heads in a plot with visible FHB symptoms. Severity (10 locations) was estimated as the mean percent disease in infected heads. Estimates of incidence and severity were made 21 days or more postanthesis, depending on rate of disease development at each location. The FHB disease index (8 locations) was estimated as (incidence $\times$ severity)/100. Fusarium damaged kernels (FDK) (6 locations) was estimated as the percentage of kernels exhibiting shriveling in a hand-harvested sample of heads. The concentration of deoxynivalenol (DON) in the grain (6 locations) was determined using the Veratox 5/5 Quantitative DON Enzyme-Linked Immunosorbent Assay (ELISA) commercially available from Neogen Corporation (Lansing, MI). Extraction and testing procedures were done according to manufacturer directions. Deoxynivalenol concentrations were determined from absorbance readings using a Neogen Awareness microwell reader with a standard curve for comparison. Plant heading date (7 locations) was recorded as the date on which $50 \%$ of the heads in each plot had emerged from the boot. Plant height (6 locations) was recorded as the distance from soil level to the tip of fully emerged heads, excluding awns.

Experiment 2. Moderately $F H B$ resistant U.S. cultivars. In this experiment, 10 cultivars were evaluated using the detached leaf assay only. The entries included four recently released U.S. commercial cultivars with moderate resistance to FHB, Roane, McCormick, NC-Neuse, and Pat, the USFHBN entries 1 (Ernie), 2 (Coker 9835), 20, 28, and 30 selected on the basis of results from experiment 1 , and the Irish FHB susceptible spring wheat cultivar Alexandria. The detached leaf assay was repeated in two separate replicated experiments using the protocols described for experiment 1 . An experimental unit consisted of four detached leaves in a single petri dish inoculated with one isolate of $M$. nivale var. majus. Five different isolates (replications) of M. nivale var. majus were utilized. The overall entry means across were based on observations on 20 detached leaves.
Statistical analysis. The detached leaf assays were analyzed using the Genstat V software. The GLM procedure of the SAS software (SAS Institute, Cary, NC) was utilized in the analysis of the multilocation field data. Entries and locations were considered random variables. Correlations between detached leaf and field data were estimated using the SAS CORR procedure. The SAS STEPWISE procedure was utilized to explore the relationship between the independent variables incubation period, latent period, and lesion length from the detached leaf assay and the dependent variables from field estimates of FHB resistance. This multiple linear regression procedure used the forward-selection method with respect to independent variables entering the model. The significance level for a variable to be added to the model was set at 0.15 .

\section{RESULTS}

Experiment 1. USFHBN entries. Significant differences were observed among entries for all variables measured in both the detached leaf assay (means of each entry over the three replicated experiments) and $F$. graminearum-inoculated field nurseries (Table 2). Entry rankings based on these variables are presented in Table 3. The moderately FHB resistant check cultivar Ernie (entry 1) was superior to the FHB susceptible check Coker 9835 (entry 2) for all FHB resistance variables, with the exception of DON concentration, which was not significantly lower in Ernie (Table 2). Entries 28, 9, 8, 7, and Ernie had the greatest resistance to FHB ranked over incidence, severity, index, FDK, and DON (Table 3 ). Entry 28 was particularly notable, as this genotype had the greatest FHB resistance averaged over all disease parameters. In contrast, entries 10,12,16,18, and Coker 9835 were the most susceptible to FHB averaged over the same variables.

Solstice and Frontana showed among the longest incubation and latent periods and shortest lesion lengths, and Alexandria and Sumai 3 among the shortest incubation and latent periods and longest lesion lengths (Table 2). These results agreed with those reported previously (2). Entry 28 was particularly notable, as it had the shortest incubation period of any genotype in the detached leaf assay showing symptoms of initial damage to the leaf surface in only 1.63 days after inoculation, but it had a relatively long latent period comparable to that of the moderately FHB resistant UK cultivar Solstice. Ernie (entry 1), the USFHBN FHB resistant control, had one of the shortest incubation periods. Correlation coefficients between individual partial disease resistance components in the detached leaf assay, using the mean data of the three replicated experiments (Table 4), were significant; however, they were lower than previously reported between incubation and latent periods $(r=$ 
0.42; Table 4). Poor agreement between incubation period and latent period was particularly notable in entry 28 , which had the shortest incubation period of all entries but one of the longest latent periods. When means for entry 28 were excluded from the data set, the correlation coefficient between incubation and latent periods was closer to that previously reported for European commercially grown wheat cultivars (2) (Table 4). The correlation between incubation period and lesion length increased to -0.63 in the absence of entry 28 . Lesion length showed a relatively high correlation with latent period $(r=-0.88$ or -0.87 ; Table 4) regardless of the inclusion of data for entry 28.

Overall, correlations between field variables indicated significant associations in all pair-wise combinations between incidence, severity, index, FDK, and DON. These correlations indicated high levels of agreement, although not complete, between FHB parameters measured in the field. Correlations were not significant between any FHB parameters and heading date or plant height. Incubation period was the only detached leaf component that had significant linear correlations with field estimates of FHB resistance. Longer incubation periods in the detached leaf assay were associated with greater FHB disease levels measured by incidence, severity, FDK, and DON content (Table 4). The correlation was higher for FHB incidence than for severity or other FHB disease parameters. Latent period was significantly correlated with plant height only; longer latent periods were associated with shorter plant height. Incubation period and lesion length were not correlated with heading date or plant height.

Incubation period and lesion length were the most important variables from the detached leaf assay for the prediction of FHB resistance among this set of genotypes identified using the STEPWISE procedure. These two independent variables together accounted for $54 \%$ of the variation in field incidence. However, a model that included incubation period alone accounted for $45 \%$ of the variation in field incidence. None of the remaining models included more than one significant independent variable; incubation period accounted for $27 \%$ of the variation in se- verity, $23 \%$ of the variation in index, $30 \%$ of the variation in FDK, and $26 \%$ of the variation in DON. The predictive value of incubation period is reflected in FHB performance of lines selected for short (entries 28, 7, 23, 24, and Ernie) versus long (entries 30, 20, 10, 25, and 15) incubation period (Table 3 ). The five short incubation period lines had a reduction in mean incidence of $20 \%$, mean severity of $16 \%$, mean index of $15 \%$, mean FDK of $12 \%$, and mean DON of $11 \%$ in comparison with the five longest incubation lines.

Experiment 2. Moderately FHB resistant U.S. cultivars. Differences among entries for detached leaf assay partial disease resistance components in both replicates of experiment 2 reflected what was observed among USFHBN entries in experiment 1 . Entry 20 showed the longest incubation and latent periods and lesion length, while Ernie (entry 1) and Alexandria had the shortest incubation and latent periods and longest lesion lengths. Entry 28 again had the shortest incubation period but had among the longest latent periods and shortest lesion lengths. Across both experiments, the moderately resistant U.S.

Table 2. Disease reactions, heading date, and plant height for wheat genotypes inoculated with Microdochium nivale in the detached leaf assay and Fusarium graminearum in field evaluations during the 2001-2002 season

\begin{tabular}{|c|c|c|c|c|c|c|c|c|c|c|c|}
\hline \multirow[b]{2}{*}{ Entry } & \multirow[b]{2}{*}{ Cultivar/designation } & \multicolumn{3}{|c|}{ Detached leaf assay } & \multicolumn{7}{|c|}{ Multilocation field evaluations } \\
\hline & & $\begin{array}{l}\text { Incubation } \\
\text { period } \\
\text { (days) }\end{array}$ & $\begin{array}{l}\text { Latent } \\
\text { period } \\
\text { (days) }\end{array}$ & $\begin{array}{l}\text { Lesion } \\
\text { length } \\
(\mathrm{mm})\end{array}$ & $\begin{array}{c}\text { Incidence } \\
(\%)\end{array}$ & $\begin{array}{c}\text { Severity } \\
(\%)\end{array}$ & $\begin{array}{c}\text { Index } \\
(\%)\end{array}$ & $\begin{array}{c}\text { FDK } \\
(\%)\end{array}$ & $\begin{array}{c}\text { DON } \\
(\mathbf{p p m})\end{array}$ & $\begin{array}{c}\text { Heading } \\
\text { date } \\
\text { (days) }\end{array}$ & $\begin{array}{c}\text { Plant } \\
\text { height } \\
(\mathrm{cm})\end{array}$ \\
\hline 1 & ERNIE & 1.88 & 6.47 & 7.42 & 52.6 & 13.5 & 12.2 & 14.5 & 12.6 & 125 & 81 \\
\hline 2 & COKER 9835 & 2.70 & 6.71 & 6.94 & 86.5 & 45.1 & 43.4 & 37.2 & 17.9 & 129 & 79 \\
\hline 3 & AR93095-4-1 & 2.61 & 6.58 & 6.96 & 60.1 & 18.8 & 16.4 & 18.2 & 9.0 & 129 & 94 \\
\hline 4 & AR93035-4-2 & 2.63 & 6.48 & 6.88 & 61.2 & 20.6 & 17.0 & 21.6 & 13.3 & 129 & 86 \\
\hline 5 & AR93035-7-1 & 2.24 & 6.07 & 7.08 & 61.3 & 21.3 & 19.0 & 23.1 & 14.4 & 128 & 89 \\
\hline 6 & AR922-5-1 & 2.28 & 5.62 & 8.94 & 56.2 & 16.4 & 14.5 & 23.5 & 13.2 & 126 & 97 \\
\hline 7 & B961378 & 2.02 & 6.86 & 6.95 & 55.7 & 15.8 & 12.2 & 15.7 & 7.8 & 129 & 84 \\
\hline 8 & B980416 & 2.32 & 6.68 & 7.12 & 52.2 & 14.0 & 12.5 & 14.5 & 7.2 & 128 & 86 \\
\hline 9 & B980582 & 2.43 & 6.53 & 8.02 & 56.3 & 13.7 & 11.1 & 13.7 & 6.2 & 124 & 89 \\
\hline 10 & D98*9762 & 3.01 & 7.03 & 5.77 & 82.7 & 42.7 & 43.7 & 36.3 & 31.6 & 128 & 89 \\
\hline 11 & D98*9764 & 2.68 & 6.58 & 7.67 & 77.6 & 36.4 & 33.0 & 32.2 & 28.4 & 127 & 91 \\
\hline 12 & D98*9770 & 2.59 & 5.90 & 7.55 & 80.2 & 53.0 & 45.6 & 40.7 & 27.0 & 128 & 94 \\
\hline 13 & D98-9213 & 2.90 & 6.40 & 7.08 & 70.8 & 32.7 & 29.9 & 30.1 & 18.5 & 128 & 91 \\
\hline 14 & D97-6075 & 2.61 & 6.72 & 7.40 & 74.4 & 34.7 & 33.4 & 34.7 & 19.0 & 127 & 91 \\
\hline 15 & GA931241E16 & 2.99 & 6.36 & 7.14 & 79.5 & 41.5 & 38.0 & 30.0 & 23.1 & 129 & 91 \\
\hline 16 & GA93052E42 & 2.46 & 6.49 & 7.08 & 77.0 & 52.1 & 52.4 & 36.2 & 34.7 & 127 & 79 \\
\hline 17 & GA931463E27 & 2.62 & 6.33 & 8.33 & 70.1 & 27.8 & 24.4 & 31.4 & 13.3 & 127 & 81 \\
\hline 18 & GA931470E62 & 2.74 & 6.78 & 6.10 & 82.0 & 48.9 & 46.5 & 39.9 & 17.7 & 125 & 76 \\
\hline 19 & GA921233E17 & 2.72 & 6.28 & 7.58 & 64.2 & 36.2 & 29.9 & 31.1 & 16.0 & 126 & 91 \\
\hline 20 & MDV11-52 & 3.07 & 7.78 & 5.03 & 72.2 & 29.0 & 22.6 & 27.0 & 16.3 & 127 & 79 \\
\hline 21 & NC98-22251 & 2.67 & 6.94 & 6.00 & 70.3 & 31.4 & 27.2 & 28.1 & 13.5 & 128 & 84 \\
\hline 22 & NC98-26189 & 2.21 & 5.65 & 9.97 & 68.9 & 21.6 & 20.0 & 19.6 & 12.2 & 127 & 81 \\
\hline 23 & NC98-26192 & 2.09 & 5.70 & 9.52 & 72.6 & 23.6 & 22.5 & 20.0 & 16.8 & 127 & 86 \\
\hline 24 & NC98-27513 & 2.17 & 6.51 & 7.19 & 57.7 & 17.1 & 16.1 & 11.3 & 9.2 & 129 & 86 \\
\hline 25 & VA01W447 & 3.00 & 6.71 & 5.25 & 69.6 & 21.7 & 17.3 & 20.0 & 10.2 & 126 & 86 \\
\hline 26 & VA01W461 & 2.58 & 6.97 & 6.32 & 55.4 & 14.7 & 12.3 & 23.0 & 15.9 & 128 & 89 \\
\hline 27 & VA01W462 & 2.83 & 7.24 & 5.00 & 74.1 & 25.5 & 20.9 & 23.7 & 19.1 & 126 & 81 \\
\hline 28 & VA01W476 & 1.63 & 7.13 & 5.61 & 35.0 & 9.9 & 9.0 & 12.2 & 2.5 & 123 & 79 \\
\hline 29 & VA00W566 & 2.74 & 6.28 & 6.61 & 67.6 & 25.2 & 24.6 & 22.0 & 18.5 & 128 & 86 \\
\hline \multirow[t]{8}{*}{30} & VA00W562 & 3.18 & 7.23 & 5.63 & 67.4 & 26.5 & 23.8 & 22.1 & 21.1 & 129 & 76 \\
\hline & SOLSTICE & 2.63 & 7.35 & 5.20 & $\ldots$ & $\ldots$ & $\ldots$ & $\ldots$ & $\ldots$ & $\ldots$ & $\ldots$ \\
\hline & FRONTANA & 2.82 & 6.85 & 6.29 & $\ldots$ & $\ldots$ & $\ldots$ & $\ldots$ & $\ldots$ & $\ldots$ & $\ldots$ \\
\hline & SUMAI \#3 & 2.07 & 6.22 & 7.20 & $\ldots$ & $\ldots$ & $\ldots$ & $\ldots$ & $\ldots$ & $\ldots$ & $\ldots$ \\
\hline & ALEXANDRIA & 2.03 & 5.83 & 8.68 & $\ldots$ & $\ldots$ & $\ldots$ & $\ldots$ & $\ldots$ & $\ldots$ & $\ldots$ \\
\hline & Mean & 2.53 & 6.57 & 6.99 & 67.0 & 27.7 & 25.0 & 25.2 & 16.1 & 127.0 & 34.0 \\
\hline & LSD (0.05) & 0.38 & 0.49 & 1.49 & 12.3 & 8.1 & 9.4 & 10.6 & 9.5 & 2.0 & 1.9 \\
\hline & $\mathrm{CV}(\%)$ & 9.3 & 4.6 & 13.4 & 18.4 & 36.3 & 41.7 & 40.5 & 56.7 & 1.3 & 4.9 \\
\hline
\end{tabular}


cultivars McCormick, NC-Neuse, and Pat had significantly longer incubation periods than Ernie (entry 1); none of the U.S. cultivars were significantly different from Coker 9835 (entry 2) for any of the detached leaf parameters (experiment 2, repeat 1: incubation period, $P<0.001$ [Fig. 1A]; latent period, $P<0.01$ [Fig. 1B]; and lesion length,
$P<0.001$ [Fig. 1C]) (experiment 2, repeat 2: incubation period, $P<0.001$ [Fig. 1D]; latent period, $P<0.001$ [Fig. 1E]; and lesion length, $P<0.001$ [Fig. 1F]).

\section{DISCUSSION}

We found that a longer incubation period in the detached leaf assay was corre- lated with higher levels of FHB in field evaluations of advanced generation U.S. breeding lines and cultivars in the USFHBN. These results contrasted with those reported previously for Irish and UK cultivars $(2,8)$, but agreed with those reported for the Chinese cultivar Sumai 3 and some CIMMYT lines containing di-

Table 3. Wheat genotype rankings for disease reactions following inoculation with Microdochium nivale in the detached leaf assay and Fusarium graminearum in field evaluations during the 2001-2002 season $^{\mathrm{a}}$

\begin{tabular}{|c|c|c|c|c|c|c|c|c|c|}
\hline \multirow[b]{2}{*}{ Entry no. } & \multirow[b]{2}{*}{ Cultivar/designation } & \multicolumn{3}{|c|}{ Detached leaf assay } & \multicolumn{5}{|c|}{ Multilocation field evaluations } \\
\hline & & $\begin{array}{c}\text { Incubation } \\
\text { period (days) }\end{array}$ & $\begin{array}{c}\text { Latent } \\
\text { period (days) }\end{array}$ & $\begin{array}{c}\text { Lesion } \\
\text { length }(\mathbf{m m})\end{array}$ & $\begin{array}{c}\text { Incidence } \\
(\%)\end{array}$ & $\begin{array}{c}\text { Severity } \\
(\%)\end{array}$ & $\begin{array}{c}\text { Index } \\
(\%)\end{array}$ & $\begin{array}{c}\text { FDK } \\
(\%)\end{array}$ & $\begin{array}{r}\text { DON } \\
(\mathbf{p p m})\end{array}$ \\
\hline 1 & ERNIE & 2 & 11 & 22 & 3 & 2 & 3 & 4 & 9 \\
\hline 2 & COKER 9835 & 21 & 20 & 12 & 30 & 27 & 26 & 28 & 20 \\
\hline 3 & AR93095-4-1 & 15 & 17 & 14 & 9 & 9 & 9 & 7 & 5 \\
\hline 4 & AR93035-4-2 & 17 & 12 & 11 & 10 & 10 & 10 & 11 & 11 \\
\hline 5 & AR93035-7-1 & 7 & 5 & 15 & 11 & 11 & 12 & 15 & 14 \\
\hline 6 & AR922-5-1 & 8 & 1 & 28 & 6 & 7 & 7 & 16 & 10 \\
\hline 7 & B961378 & 3 & 23 & 13 & 5 & 6 & 4 & 6 & 4 \\
\hline 8 & B980416 & 9 & 18 & 18 & 2 & 4 & 6 & 5 & 3 \\
\hline 9 & B980582 & 10 & 15 & 26 & 7 & 3 & 2 & 3 & 2 \\
\hline 10 & D98*9762 & 28 & 26 & 6 & 29 & 26 & 27 & 27 & 29 \\
\hline 11 & D98*9764 & 19 & 16 & 25 & 25 & 24 & 23 & 24 & 28 \\
\hline 12 & D98*9770 & 13 & 4 & 23 & 27 & 30 & 28 & 30 & 27 \\
\hline 13 & D98-9213 & 25 & 10 & 16 & 19 & 21 & 21 & 21 & 22 \\
\hline 14 & D97-6075 & 14 & 21 & 21 & 23 & 22 & 24 & 25 & 23 \\
\hline 15 & GA931241E16 & 26 & 9 & 19 & 26 & 25 & 25 & 20 & 26 \\
\hline 16 & GA93052E42 & 11 & 13 & 17 & 24 & 29 & 30 & 26 & 30 \\
\hline 17 & GA931463E27 & 16 & 8 & 27 & 17 & 18 & 18 & 23 & 12 \\
\hline 18 & GA931470E62 & 22 & 22 & 8 & 28 & 28 & 29 & 29 & 19 \\
\hline 19 & GA921233E17 & 20 & 6 & 24 & 12 & 23 & 22 & 22 & 16 \\
\hline 20 & MDV11-52 & 29 & 30 & 2 & 20 & 19 & 16 & 18 & 17 \\
\hline 21 & NC98-22251 & 18 & 24 & 7 & 18 & 20 & 20 & 19 & 13 \\
\hline 22 & NC98-26189 & 6 & 2 & 30 & 15 & 12 & 13 & 8 & 8 \\
\hline 23 & NC98-26192 & 4 & 3 & 29 & 21 & 14 & 15 & 10 & 18 \\
\hline 24 & NC98-27513 & 5 & 14 & 20 & 8 & 8 & 8 & 1 & 6 \\
\hline 25 & VA01W447 & 27 & 19 & 3 & 16 & 13 & 11 & 9 & 7 \\
\hline 26 & VA01W461 & 12 & 25 & 9 & 4 & 5 & 5 & 14 & 15 \\
\hline 27 & VA01W462 & 24 & 29 & 1 & 22 & 16 & 14 & 17 & 24 \\
\hline 28 & VA01W476 & 1 & 27 & 4 & 1 & 1 & 1 & 2 & 1 \\
\hline 29 & VA00W566 & 23 & 7 & 10 & 14 & 15 & 19 & 12 & 21 \\
\hline 30 & VA00W562 & 30 & 28 & 5 & 13 & 17 & 17 & 13 & 25 \\
\hline
\end{tabular}

${ }^{a}$ Rank of 1 refers to the lowest Fusarium head blight (FHB) disease parameters (most resistant), and in the detached leaf assay the shortest incubation and latent periods and the shortest lesion lengths.

Table 4. Correlation coefficients between Fusarium head blight (FHB) variables from the detached leaf assay and field nurseries ${ }^{\text {a }}$

\begin{tabular}{|c|c|c|c|c|c|c|c|c|c|c|}
\hline & $\begin{array}{c}\text { Incubation } \\
\text { period }\end{array}$ & $\begin{array}{l}\text { Latent } \\
\text { period }\end{array}$ & $\begin{array}{l}\text { Lesion } \\
\text { length }\end{array}$ & Incidence & Severity & Index & FDK & DON & $\begin{array}{l}\text { Heading } \\
\text { date }\end{array}$ & $\begin{array}{l}\text { Plant } \\
\text { height }\end{array}$ \\
\hline Incubation period & & $0.42 * \mathrm{~b}$ & -0.47 & 0.67 & 0.52 & 0.48 & 0.55 & 0.51 & 0.10 & $\ldots^{c}$ \\
\hline Latent period & 0.57 & & -0.86 & $\cdots$ & $\ldots$ & $\ldots$ & $\cdots$ & $\cdots$ & $\cdots$ & -0.48 \\
\hline Lesion length & -0.63 & -0.87 & & $\cdots$ & $\cdots$ & $\cdots$ & $\cdots$ & $\cdots$ & $\cdots$ & $\cdots$ \\
\hline Incidence & 0.56 & $\ldots$ & $\ldots$ & & 0.87 & 0.85 & 0.83 & 0.76 & $\ldots$ & $\ldots$ \\
\hline Severity & 0.46 & $\ldots$ & $\ldots$ & 0.88 & & 0.99 & 0.93 & 0.81 & $\ldots$ & $\ldots$ \\
\hline Index & $0.42 *$ & $\ldots$ & $\cdots$ & 0.87 & 0.99 & & 0.91 & 0.83 & $\cdots$ & $\ldots$ \\
\hline FDK & 0.49 & $\ldots$ & $\cdots$ & 0.83 & 0.93 & 0.91 & & 0.77 & $\cdots$ & $\ldots$ \\
\hline $\mathrm{DON}$ & 0.42 & ... & .. & 0.73 & 0.80 & 0.82 & 0.75 & & $\cdots$ & $\ldots$ \\
\hline Heading date & $\cdots$ & $\cdots$ & $\cdots$ & $\cdots$ & $\cdots$ & $\cdots$ & $\cdots$ & $\cdots$ & & $\cdots$ \\
\hline Plant height & $\ldots$ & -0.45 & $\ldots$ & $\ldots$ & $\ldots$ & $\ldots$ & $\ldots$ & $\ldots$ & $\ldots$ & \\
\hline
\end{tabular}

${ }^{\text {a }}$ Correlation coefficients above diagonal were based on all entries; those below diagonal did not include data for entry 28.

b $*$ significant at $P \leq 0.05$, otherwise $P \leq 0.01$.

c Not significant. 
verse sources of FHB resistance (2). Browne and Cooke (2) hypothesized that this dichotomy reflected the different genetic control of the highly effective FHB resistance such as found in Sumai 3 and the CIMMYT lines and the more moderate FHB resistance in the European cultivars.

The higher correlation of incubation period in the detached leaf assay with FHB incidence rather than with FHB severity indicates that the partial disease resistance component detected by incubation period (first appearance of damage to the leaf surface under macroscopic observation) has a greater effect at the early stages of infection, as would be expected. The present work reflects the polygenic nature of FHB resistance and the importance of methods, including the detached leaf assay and molecular mapping techniques, to determine specific components of FHB resistance, which cannot be distinguished on the basis of whole-plant resistance alone. The relationships between type II resistance and partial disease resistance components detected using the detached leaf assay of the USFHBN entries were not investigated in this paper. It has been hypothesized that genetic control of type I resistance differs from that of type II resistance $(20,24)$; however, the relationship between resistances described as type I and type II is not fully understood.

Some recently released moderately resistant U.S. cultivars, Roane, McCormick, NC-Neuse, and Pat, exhibited longer incubation periods, similar to the patterns in their European counterparts and the historically important cultivar Fontana $(2,8)$, but Ernie did not. Further evaluation of a wider range of FHB susceptible and moderately resistant U.S. commercial cultivars would be desirable to quantify the relationship between FHB resistance and partial disease resistance components which appear to differ from advanced breeding lines in the USFHBN. The present results indicate that in the case of Ernie, a moderately resistant commercial cultivar with a short incubation period, breeding may have been successful in incorporating a resistance background where a short incubation pe- riod relates to greater FHB resistance. Among the entries in the USFHBN containing exotic sources of FHB resistance, selection of entries based on long incubation and latent periods and short lesion lengths, as found in moderately FHB resistant European cultivars $(2,8)$, was not effective in identification of USFHBN lines with high levels of FHB resistance. For example, entries $10,20,25,27$, and 30 had the longest incubation and latent periods and shortest lesion lengths, but exhibited the lowest levels of FHB resistance when ranked over the five FHB variables. This reflects both the dichotomy between incubation period and FHB resistance in exotic germ plasm compared with that observed in commercially grown cultivars $(2,8)$ and the importance of FHB resistances not detected in detached leaf assay. However, the results indicate the potential of the detached leaf assay to distinguish between specific sources/mechanisms of FHB resistance, which cannot be distinguished in the whole-plant FHB reaction, when combined with data on FHB reaction and pedigree
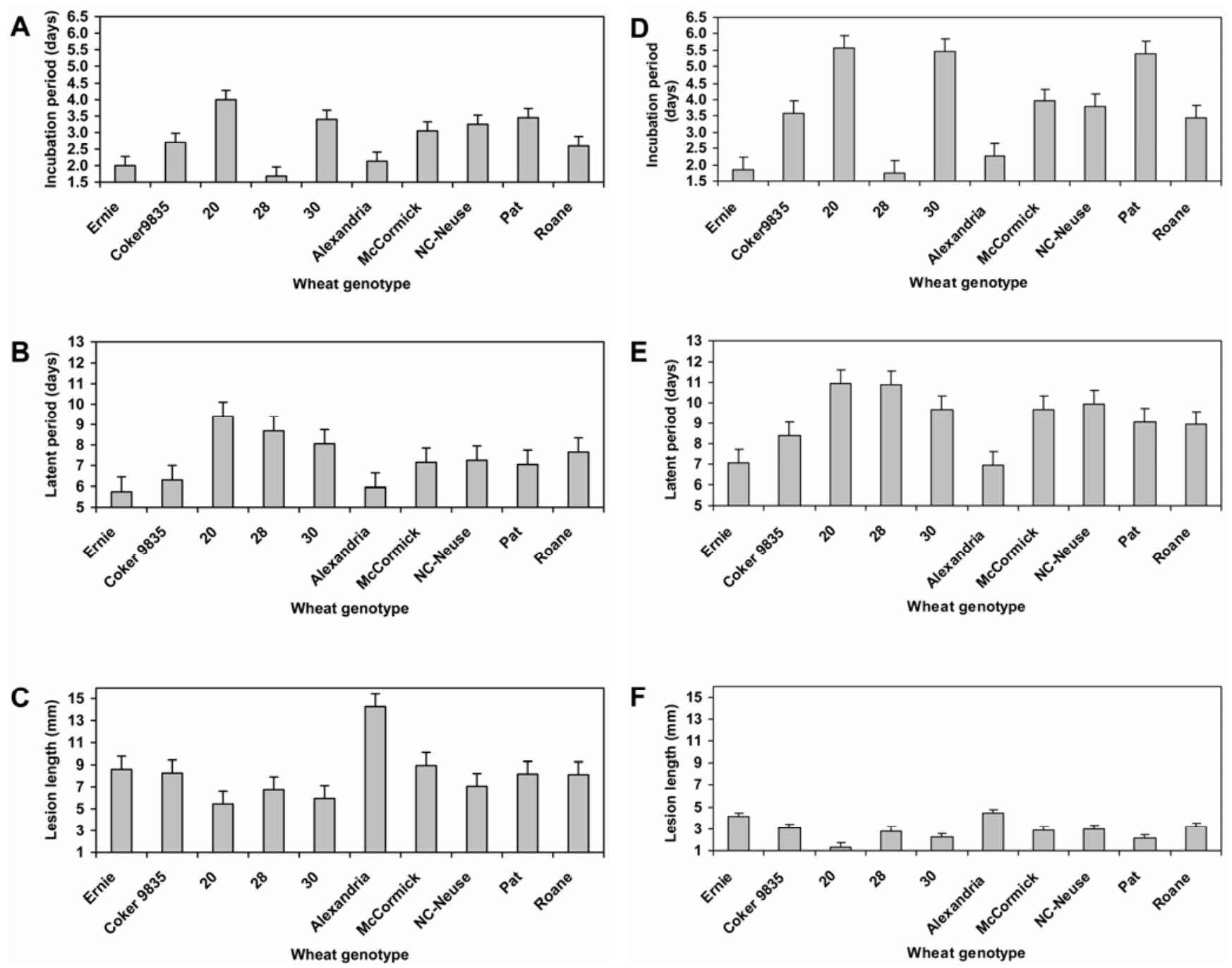

Fig. 1. A, Incubation period, $\mathbf{B}$, latent period, and $\mathbf{C}$, lesion length (experiment 2, repeat 1) and $\mathbf{D}$, incubation period, $\mathbf{E}$, latent period, and $\mathbf{F}$, lesion length (experiment 2, repeat 2) for detached leaves of wheat Uniform Southern Fusarium Head Blight Nursery (USFHBN) entries Ernie (entry 1), Coker 9835 (entry 2), 20, 28, and 30 and cultivars Alexandria, McCormick, NC-Neuse, Pat, and Roane. Bars represent standard errors of the means. 
information. This could provide breeders with valuable insight when planning crossing programs designed to combine multiple sources of FHB resistance into future cultivars.

Of particular interest is entry 28 , the most FHB resistant genotype in the USFHBN, which was developed by the doubled haploid procedure following the cross of the FHB resistant Chinese line W14 with the moderately resistant soft red winter wheat Roane. W14 contained the Sumai 3 source of FHB resistance. Following the recovery of doubled haploid plants, the population that gave rise to entry 28 was selected primarily on FHB resistance and not on agronomic performance for the southern United States. Because of this developmental history, entry 28 likely contained many of the FHB resistance factors from both $\mathrm{W} 14$ and Roane that were nonallelic or tightly linked in repulsion. Entry 28 was unique among the genotypes evaluated in this study because it had the shortest incubation period observed to date in the detached leaf assay, but among the longest latent period and smallest lesion length of USFHBN entries. This genotype may be an example of a combination of resistance sources that can be confirmed with the aid of the detached leaf assay. Although W14 was not evaluated using the detached leaf assay, Roane had a significantly longer incubation period but similar latent period and lesion length to entry 28 . The unique combination of leaf assay component means for entry 28 may reflect the presence of Sumai 3 resistance that conferred the short incubation period and Roane resistance that conferred the longer latent period and smaller lesion length. Entry 7 was another USFHBN line with good overall FHB resistance. It had a short incubation period but displayed a latent period and lesion length similar to entry 28 , although the combination of partial disease resistance components in the detached leaf assay was not as extreme as that observed in entry 28 .

However, it is not clear why longer incubation periods in moderately resistant commercial wheat cultivars are associated with greater FHB resistance, albeit more weakly than latent period $(2,8)$, and with greater FHB susceptibility in genotypes with more diverse sources of resistance. This could reflect that a short incubation period may not confer resistance if unaccompanied by additional resistance such as long latent period or resistances from more exotic sources. Browne and Cooke (3) suggested that a necrotic lesion(s) after initial infection in barley (Hordeum vulgare L.), and subsequent arrest of pathogen development in the detached leaf assay, could indicate a resistant response rather than susceptibility. Such a response, if present in wheat, could combine a short incubation period with a long latent period and short lesion length as observed in en- try 28. However, if this response occurred in whole-plant FHB resistance, it may be difficult to distinguish by visual assessment the necrosis involved in the resistant response from the development of typical symptoms of FHB in the wheat head. Tolerance of infection by the host, such as fungal colonization without symptoms of damage to detached leaves of oats (Avena sativa $\mathrm{L}$.) (3), could be undesirable if such tolerance did not inhibit mycotoxin accumulation in the developing grain. In what might be a similar tolerant reaction, Evans and Dill-Mackey (9) did not observe lesion development on the primary leaves of the moderately FHB resistant cultivar Frontana following inoculation with $F$. graminearum. However, significant DON accumulation was detected in the nonsymptomatic leaves. In contrast, large lesions but no DON accumulation occurred on the primary leaves of the moderately FHB resistant cultivar Alsen. Alsen contains Sumai 3 in its pedigree.

The diversity and complexity of the polygenic resistances to FHB ascribed to numerous chromosomal regions is reflected in the current work, as is the difficulty in the development of highly FHB resistant commercially acceptable cultivars based on the evaluation of FHB resistance in the whole plant alone. This paper investigates the development of in vitro techniques, which with molecular mapping will bring us closer to designing crosses and combinations of specific partial resistances in a more effective manner. Of particular relevance to the present work is molecular mapping of the partial disease resistance components detected using the detached leaf assay and the whole plant, which is at an advanced stage in collaborative work between researchers in Norway and Ireland. This will provide useful information to relate the observations presented in this paper with molecular mapping studies of FHB resistance sources.

\section{LITERATURE CITED}

1. Browne, R. A., and Cooke, B. M. 2004. A new method for producing mycelium-free conidial suspensions from cultures of Microdochium nivale. Eur. J. Plant Pathol. 110:87-90.

2. Browne, R. A., and Cooke, B. M. 2004. Development and evaluation of an in vitro detached leaf assay for pre-screening resistance to Fusarium head blight in wheat. Eur. J. Plant Pathol. 110:91-102.

3. Browne, R. A., and Cooke, B. M. 2004. Potential mechanisms of resistance to Fusarium head blight detected using a detached leaf assay of wheat, barley and oats. Page 829 in: VIII ESA Congress: European Agriculture in a global context; 2004 July 11-15. S. E. Jacobsen, C. R. Jensen, and J. R. Porter, eds. The Royal Veterinary and Agricultural University, Copenhagen, Denmark.

4. Campbell, K. A. G., and Lipps, P. E. 1998. Allocation of resources: Sources of variation in Fusarium head blight screening nurseries. Phytopathology 88:1078-1086.

5. Chen, P., Liu, D., and Sun, W. 1997. New counter measures of breeding for scab resistance. Pages 86-92 in: Fusarium Head Scab:
Global status and future prospects. H. J Duben, L. Gilchrist, J. Reeves, and A. McNab, eds. CIMMYT, Mexico, DF.

6. Cooke, B. M. 1980. The use of coolplates for culturing photosporogenetic fungi. Bull. Br. Mycol. Soc. 14:137-138.

7. Cox, T. S. 1991. The contribution of introduced germplasm to the development of U.S wheat cultivars. Pages 25-47 in: Use of Plant Introductions in cultivar development, Part 1. H. L. Shands and L. E. Wiesner eds. CSSA Sp. Pub. No. 17, CSSA, Madison, WI.

8. Diamond, H., and Cooke, B. M. 1999. Towards the development of a novel in vitro strategy for early screening of Fusarium ear blight resistance in adult winter wheat plants. Eur. J. Plant Pathol. 105:363-372.

9. Evans, C. K., and Dill-Macky, R. 2003. Reaction of primary leaves of 26 wheat genotypes inoculated with macroconidia of Fusarium gramimearum at the seedling stage and assessed for lesion length and deoxynivalenol accumulation at $96 \mathrm{H}$ post-inoculation. Page 138 in: Proc. Nat. Fusarium Head Blight Forum; 2003 Dec 13-15; Bloomington, MN. S. M. Canty, J. Lewis, and R. W. Ward, eds. Michigan State University, East Lansing.

10. Gooding, R. W., Lafever, H. N., Campbell, K. G., and Herald, L. D. 1997. Registration of 'Freedom' wheat. Crop Sci. 37:1007.

11. Jeger, M. J., Gareth Jones, D., and Griffiths, E. 1983. Components of partial resistance of wheat seedlings to Septoria Nodorum. Euphytica 32: 575-584.

12. Liu, S., and Anderson, J. A. 2003. Marker assisted evaluation of Fusarium head blight resistant wheat germplasm. Crop Sci. 43:760766.

13. Liu, S., Lu, H., Davis, G. E., and McKendry, A. L. 2003. Genetic studies of scab resistance in the soft red winter wheat 'Ernie'. Pages 2123 in: Proc. Nat. Fusarium Head Blight Forum; 2003 Dec 13-15; Bloomington, MN. S. M. Canty, J. Lewis, and R. W. Ward, eds. Michigan State University, East Lansing.

14. McKendry, A. L., Berg, J. E., Tague, D. N., and Kephart, K. D. 1995. Registration of 'Ernie' soft red winter wheat. Crop Sci. 35:1513.

15. Mesterhazy, A. 1995. Types and components of resistance against FHB of wheat. Plant Breed. 114:377-386.

16. Mesterhazy, A., Bartok, T., Mirocha, C. G. and Komoroczy, R. 1999. Nature of wheat resistance to Fusarium head blight and the role of deoxynivalenol for breeding. Plant Breed. 118:97-110.

17. Otto, D., Kianian, D., Elias, S. F., Stack, E. M., and Joppa, R. W., and Joppa, L. R. 2002. Genetic dissection of a major Fusarium head blight QTL in teteraploid wheat. Plant Mol. Biol. 48:625-632.

18. Parry, D. W., Jenkinson, P., and McLeod, L. 1995. Fusarium ear blight (scab) in small grain cereals - a review. Plant Pathol. 44:207-238.

19. Rudd, J. C., Horsley, R. D., McKendry, A. L., and Elias, E. M. 2001. Host plant resistance genes for Fusarium head blight: Sources, mechanisms, and utility in conventional breeding systems. Crop Sci. 41:620-627.

20. Schroeder, H. W., and Christensen, J. J. 1963. Factors affecting resistance of wheat to scab caused by Gibberella zeae. Phytopathology 53:831-838.

21. Shen, X., Ittu, M., and Ohm, H. W. 2003. Quantitative trait loci controlling resistance to Fusarium head blight in wheat line F201R. Crop Sci. 43:850-857.

22. Stack, R. W., and McMullen, M. P. 1985. Head blighting potential of Fusarium species associated with spring wheat heads. Can. J. Plant. Pathol. 22:9-16.

23. Vanderplank, J. E. 1963. Plant Diseases: Epidemics and Control. Academic Press, London. 
24. Van Ginkel, M., Van Der Schaar, W., Zhuping, Y., and Rajaram, S. 1996. Inheritance of resistance to scab in two wheat cultivars from Brazil and China. Plant Dis. 80:863-867.

25. Walker, S. L., Leath, S., Hagler, W. M., Jr., and Murphy, J. P. 2001. Variation among isolates of

Fusarium graminearum associated with Fusa- rium head blight in North Carolina. Plant Dis. 85:404-410.

26. Wiese, M. V. 1987. Compendium of Wheat Diseases. 2nd ed. American Phytopathological Society, St. Paul, MN.

27. Wilcoxson, R. D., Kommedahl, T., Ozmon, E. A., and Windels, C. E. 1988. Occurrence of
Fusarium species in scabby wheat from Minnesota and their pathogenicity to wheat. Phytopathology 78:586-589.

28. Windels, C. E. 2000. Economic and social impacts of Fusarium head blight: Changing farms and rural communities in the Northern Great Plains. Phytopathology 90:17-21. 